\title{
Differential modulation of bovine epididymal activity by oxytocin and noradrenaline
}

\author{
Marco Mewe ${ }^{1}$, Iris Wulfsen ${ }^{2}$, Ralf Middendorff ${ }^{3}$ and Christiane K Bauer $^{1}$ \\ ${ }^{1}$ Institut für Vegetative Physiologie und Pathophysiologie and ${ }^{2}$ Institut für Pharmakologie für Pharmazeuten, UKE, \\ Universität Hamburg, Martinistr. 52, D-20246 Hamburg, Germany and ${ }^{3}$ Institut für Anatomie und Zellbiologie, Justus- \\ Liebig-Universität Gießen, D-35385 Gießen, Germany
}

Correspondence should be addressed to M Mewe; Email: mewe@uke.uni-hamburg.de

\begin{abstract}
Passage of spermatozoa through the epididymis and emission of sperm during ejaculation are based on spontaneous and induced contractions of epididymal peritubular muscle layers. This study deals with the ejaculation-relevant factors noradrenaline (NA) and oxytocin (OT) and their contractile effects in the course of the bovine epididymal duct. Muscle tension recording revealed excitatory effects of NA in all duct regions. A peculiarity was found in a duct section between the mid-cauda and ductus deferens, where the responsiveness to NA was particularly faint in comparison with the adjacent regions. NA-induced contraction was primarily mediated by postjunctional $\alpha_{2}$-adrenoceptors (ADRA) in the caput and corpus regions, and by $\alpha_{1}$-ADRA in the cauda region. Contrary to NA, OT exerted regionally varying effects. The peptide induced contraction in intact and epithelium-denuded caput as well as in epithelium-denuded corpus segments but had a relaxant net effect in intact corpus and proximal cauda segments. Within the mid-cauda, OT evoked strong contraction, which progressively decreased distally. Receptor specificity of the epididymal OT effects was verified using the selective OT receptor (OTR) agonist $\left[\mathrm{Thr}^{4}, \mathrm{Gly}^{7}\right]$ OT and vasopressin. OTR immunoreactivity was detected in the epididymal peritubular muscle wall and epithelial principal cells. RT-PCR analysis confirmed the presence of OTR in all duct regions. In summary, different contractile responses to OT and NA occur in the course of the epididymal duct, possibly preventing excessive sperm transport through the corpus and serving orthograde emission of sperm during ejaculation.

Reproduction (2007) 134 493-501
\end{abstract}

\section{Introduction}

Passage of sperm through the sparsely innervated proximal epididymal duct regions (i.e. caput and corpus) is largely a consequence of spontaneous phasic contractions (SCs) of peritubular smooth muscle layers, whereas propulsion of sperm within the densely innervated cauda and emission of sperm at ejaculation are predominantly neurogenic in origin (Cosentino \& Cockett 1986, Ricker 1998, Mewe et al. 2006a). Epididymal sperm transit is of critical importance for epithelium-dependent sperm maturation processes (Moore 1995) and fertility (Ratnasooriya \& Wadsworth 1990, Ricker et al. 1997).

Several local factors like endothelin-1 (Peri et al. 1998), cyclic GMP (Mewe et al. 2006b) and prostaglandins (Cosentino et al. 1984, Mewe et al. 2006a) appear to be involved in the modulation of epididymal phasic activity. It is also well established that oxytocin (OT) is implicated in many male reproductive functions including steroidogenesis and reproductive tract contractility
(Ivell et al. 1997, Thackare et al. 2006). OT has been shown to regulate epididymal basal contractility and stimulate sperm release from the epididymal storage at ejaculation in several species (Melin 1970, Hib 1974, Knight 1974, Berndtson \& Igboeli 1988, Nicholson et al. 1999, Studdard et al. 2002, Filippi et al. 2003). The circulating level of OT in mammals is in the picomolar range; however, a pulse in systemic OT has been described at ejaculation (Schams et al. 1982, Murphy et al. 1987). Apart from the hypothalamopituitary system and testicular Leydig cells, the epididymal principal cells are supposed to be a source of OT (Harris et al. 1996, Einspanier \& Ivell 1997, Assinder et al. 2000, Filippi et al. 2005), supporting the role of the peptide hormone as paracrine modulator of epididymal sperm transit. A number of studies have confirmed the presence of OT receptors (OTRs) and specific OTR mRNA within the epididymis of several species (Maggi et al. 1987, Einspanier \& Ivell 1997, Frayne \& Nicholson 1998, Whittington et al. 2001, Filippi et al. 2002). 
Epididymal peristalsis and ejaculation are also under the control of autonomic signalling (Ricker 1998). Particularly, the cauda region receives postganglionic innervation from hypogastric and spermatic nerves supplying sympathetic and parasympathetic innervation to the epididymis (El-Badawi \& Schenk 1967, Hodson 1970, Baumgarten et al. 1971, Ivell et al. 1997). Predominantly, noradrenergic output stimulates epididymal muscle activity and emission of sperm during ejaculation (Pholpramool et al. 1984, Billups et al. 1990, Kempinas et al. 1998). The effects of noradrenaline (NA) seem to be primarily mediated not only by postjunctional $\alpha_{1}$-adrenoceptors (ADRA; Pholpramool et al. 1984, Ventura \& Pennefather 1991, Chaturapanich et al. 2002), but also by $\alpha_{2}$-ADRA (Haynes \& Hill 1996, Chaturapanich et al. 2002).

Since in several species both neurohypophysial OT and the neurotransmitter NA appear to be associated with ejaculation, the question arises of their epididymal contractile effects with regard to sperm maturation and orthograde emission of sperm. The purpose of our study was to systematically investigate the contractile potency and distribution of postjunctional receptors of both ejaculation-relevant factors in different (sub)regions of the bovine epididymal duct, which exhibits a morphological subdivision similar to that in the human (Glover \& Nicander 1971).

\section{Materials and Methods}

\section{Tissue preparation}

Epididymal tissue was obtained from sexually mature bulls in a local abattoir, 10-15 min after slaughtering. The epididymides were placed in ice-cold $\mathrm{Ca}^{2+}$-free Hanks' balanced salt solution (HBSS; Life Technologies Inc.) for transport to the laboratory. For immunohistochemical analyses, tissue samples of different regions of the duct (caput-corpus-cauda) were fixed in Bouin's fluid for $24 \mathrm{~h}$ at $20^{\circ} \mathrm{C}$. For muscle tension studies, segments of the epididymal duct were separated in $\mathrm{Ca}^{2+}$-free HBSS by carefully dissecting the surrounding tissue under a stereomicroscope. Removal of the epididymal epithelium was carried out with $1 \%$ Triton X-100 (Merck-Calbiochem) in PBS (3 min) using a Hamilton syringe (see also Mewe et al. 2006a). Before use in tissue bath assays, the segments were stored for at least $2 \mathrm{~h}$ in DMEM (Life Technologies Inc.) at $4{ }^{\circ} \mathrm{C}$.

\section{Tension studies}

Isometric tension studies were performed essentially as previously reported (Mewe et al. 2006a). In brief, segments of different regions of the epididymal duct were mounted with silk thread in an organ bath $(15 \mathrm{ml}$ volume). Preparations were equilibrated in modified Krebs bicarbonate Ringer (containing (in $\mathrm{mM}$ ): $\mathrm{NaCl}$
118, $\mathrm{KCl} 4.75, \mathrm{KH}_{2} \mathrm{PO}_{4} 1.2, \mathrm{MgSO}_{4} 1.2, \mathrm{CaCl}_{2} 2.5$, $\mathrm{NaHCO}_{3} 25$ and D-glucose 11; continuously gassed with carbogen to provide oxygenation and $\mathrm{pH}$ 7.3-7.4) at $33-34{ }^{\circ} \mathrm{C}$. Mechanical responses were recorded by a SG4-90 force-displacement transducer (Hugo Sachs, Freiburg, Germany). The output of the transducer was digitized at $1 \mathrm{~Hz}$ using a Metrabyte DAS 1202 (Keithley Instruments, Cleveland, $\mathrm{OH}, \mathrm{USA}$ ) interface. The Triton X-100-pretreated and the intact proximal duct and cauda segments were stretched incrementally to a preload tension of around 3,6 and $10 \mathrm{mN}$ respectively. Preparations were allowed to equilibrate for $60 \mathrm{~min}$ and relax to a steady-state resting tension to prevent 'stretch-induced' contractions. Data collection was carried out using a DOS program developed by $\mathrm{P}$ Bassalay (Institute of Physiology, UKE, Hamburg, Germany). Further data processing was performed with Sigma Plot 7.101 (SPSS, Chicago, IL, USA). OT and NA were added to the bath medium at final concentrations of $500 \mathrm{nM}$ and $10 \mu \mathrm{M}$ respectively. The concentration of OT was chosen following preliminary trials revealing a maximum effect of the hormone on proximal epididymal duct contractility between 100 and $500 \mathrm{nM}$.

\section{Immunohistochemistry}

Immunohistochemical analyses were carried out as previously described (Middendorff et al. 1997). Briefly, paraffin sections of different duct regions were incubated with mouse antioxytocin receptor (OTR) MAB O-2F8 (1:100; Rohto Pharmaceutical, Osaka, Japan) overnight. Biotinylated rabbit antimouse IgG (Dako, Hamburg, Germany) was used as secondary antibody. Visualization of immunoreactivity was carried out with the peroxidase-antiperoxidase technique in combination with the avidin-biotin-peroxidase complex method. Peroxidase activity was visualized using the nickelglucose oxidase technique. For negative controls, the primary antibody was omitted or replaced by normal mouse serum to indicate any non-specific binding.

\section{RNA isolation and RT-PCR}

Immediately after preparation, epididymal tissues were frozen in liquid nitrogen. RNA preparation was performed according to the protocol of Chomczynski \& Sacchi (1987). Total RNAs were employed in reverse transcriptase PCR (RT-PCR) experiments using the following oligonucleotide primer sequences for amplification of the OTR (GenBank database: accession no. NM_174134; nucleotides 681-1230): forward 5'-GCTGCGCGAGGTGGCCGACG-3'; reverse 5'-AGGCCGGCTGCCTTTCAGGC-3'. Amplified DNA fragments were analyzed by agarose gel electrophoresis and sequencing. To exclude genomic amplification, oligonucleotide primers spanning an intron sequence of 
about 7400 bp were used. Analysis using $\mathrm{H}_{2} \mathrm{O}$, instead of template, was performed as negative control.

\section{Chemicals}

OT was purchased from Bachem (Heidelberg, Germany). $\left[\mathrm{Thr}^{4}\right.$, Gly $\left.^{7}\right] \mathrm{OT}$ (xOT), arginine vasopressin (AVP), NA, prazosin, yohimbine, $N_{\omega}$-nitro-L-arginine methyl ester (L-NAME), 4-aminopyridine (4-AP) and indomethacin were obtained from Sigma. Stock solutions of NA and indomethacin were prepared in ethanol. The final concentration of the solvent in the perfusate was $<0.03 \%$. All other substances were dissolved in distilled water.

\section{Statistical analysis}

Experimental data are given as means \pm S.E.M. $n$ represents the number of tissue samples derived from different animals. For calculation of $\mathrm{EC}_{50}$ values, concentration-response curves were analyzed using GraphPad Prism 4 (GraphPad Software, San Diego, CA, USA). Student's two-tailed paired $t$-test was used to assess statistical significance. $P$ values $<0.05$ were considered significant.

\section{Results}

\section{Effects of OT and NA along the epididymal duct}

Following the data ascertained by isometric tension recordings, the bovine epididymis was regionally subdivided as illustrated in Fig. 11. A distinct variation in the contractile effects of OT (500 nM; results given in Table 1$)$ and NA $(10 \mu \mathrm{M})$ in the course of the epididymal duct was found. In the caput, OT induced a profound contraction, with significant increases in both SC frequency (by $21.7 \pm 2.4 \%)$ and basal tone $(P<0.05$, $n=5$; Fig. 1A). By contrast, a sustained relaxing effect of OT was noted in the corpus ( $n=5$; Fig. 1C) and the cauda (p) $(n=3$; Fig. 1E). The relaxation at the level of the corpus was characterized by a significant reduction in basal tone and a decrease in SC frequency by $-12.0 \pm 3.8 \%(P<0.05)$. At the level of the mid-cauda (cauda $(\mathrm{m})$ ), OT induced particularly strong contraction $(n=3$; Fig. 1F), whereas almost no contractile response was observed in the ductus deferens (pars epididymica (p.ep.), $n=3$; Fig. $1 \mathrm{H}$ ).

Contrary to OT, NA exerted contractile effects all along the epididymal duct ( $n=4$ per region; Fig. $1 \mathrm{~B}$ and $\mathrm{D}-\mathrm{H}$ ). The degree of effectiveness (calculated by the relative efficiency in increasing basal tone; Fig. 1) progressively increased from the corpus to the cauda $(\mathrm{m})$ and then decreased again towards the ductus deferens (p.ep.). The contraction elicited by NA was limited to about 10 and $5 \mathrm{~min}$ in duration in the cauda $(\mathrm{m})$ and ductus deferens (p.ep.) respectively. A peculiarity was found in the distal
A

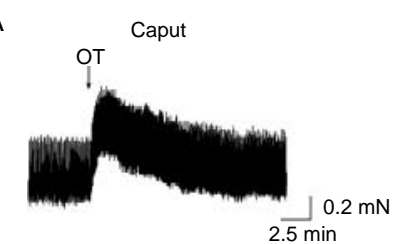

C

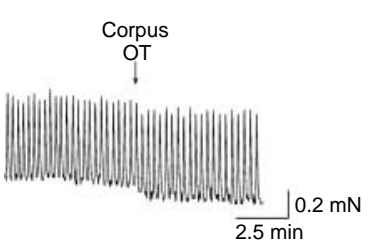

B

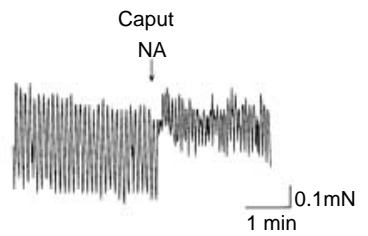

D

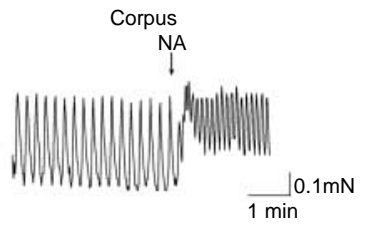

$\mathrm{E}$

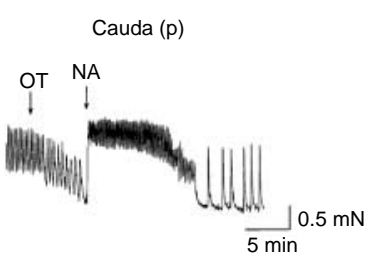

G
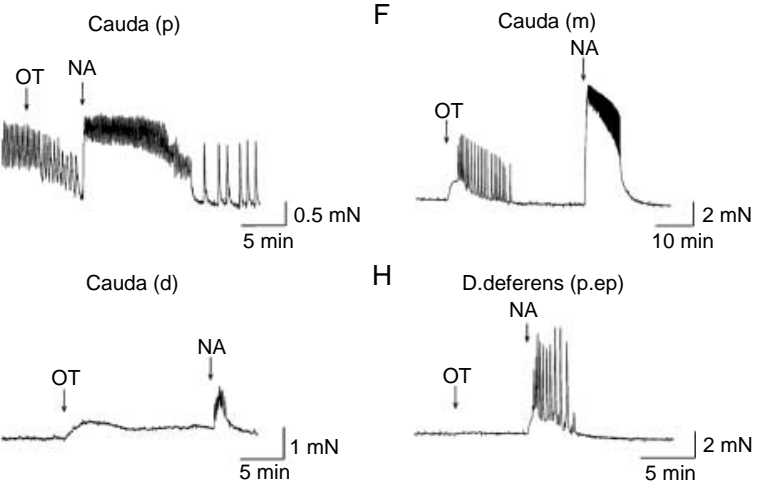

I

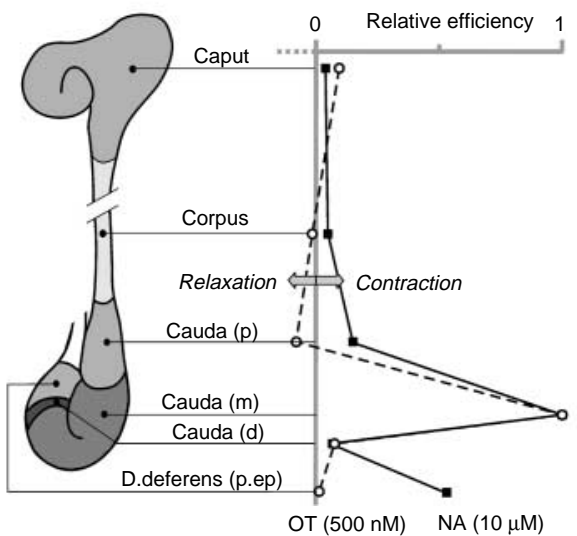

Figure 1 Contractile effects of OT and NA in the course of the bovine epididymal duct. (A-H) Representative isometric force recordings of the effects of OT (500 nM) and NA $(10 \mu \mathrm{M})$ in the indicated (sub)regions. (I) Schematic of the bovine epididymis illustrating the different (sub)regions distinguished according to morphological and functional features. On the right, the relative effects of OT and NA on epididymal muscle tone are shown. The data of representative recordings along the duct were normalized to the respective maximum effects in the cauda $(\mathrm{m})$.

cauda region (cauda (d)), a duct section of only about $10 \mathrm{~cm}$ in length between the cauda $(\mathrm{m})$ and the ductus deferens (p.ep.). This subregion is described here for the first time and could be distinguished from the adjacent duct regions by an intermediate duct diameter, allowing reproducible detection. In the cauda (d), the responsiveness to both OT and NA was strikingly weak when compared with the cauda $(\mathrm{m})$ (maximum contraction force: $0.59 \pm 0.15$ vs $4.1 \pm 0.58 \mathrm{mN}$ for OT and 
Table 1 Contractile effects of $\left[\mathrm{Thr}^{4}, \mathrm{Gly}^{7}\right] \mathrm{OT}$ (xOT), OT and arginine vasopressin (AVP) in the course of the bovine epididymal duct.

\begin{tabular}{|c|c|c|c|c|c|c|c|c|c|}
\hline & \multicolumn{4}{|c|}{ xOT } & \multicolumn{2}{|l|}{ OT } & \multicolumn{3}{|c|}{ AVP } \\
\hline & $\begin{array}{l}\mathrm{EC}_{50} \\
(\mathrm{nM})\end{array}$ & Effect & At & $n$ & Effect at $500 \mathrm{nM}$ & $n$ & $\begin{array}{l}30 \mathrm{nM} \\
(n=4)\end{array}$ & $\rightarrow$ & $300 \mathrm{nM}(n=4)$ \\
\hline \multicolumn{10}{|l|}{ Caput } \\
\hline $\begin{array}{l}\text { SC freq. } \\
\text { Tone }\end{array}$ & 19.9 & $+20.6 \pm 1.5 \%$ & $100 \mathrm{nM}$ & 4 & $+21.7 \pm 2.4 \%$ & 5 & $+^{a}$ & & ++ \\
\hline \multicolumn{10}{|c|}{  } \\
\hline $\begin{array}{l}\text { SC freq. } \\
\text { Tone }\end{array}$ & $\begin{array}{l}106 \\
335\end{array}$ & $\begin{array}{r}-16.9 \pm 1.8 \% \\
-5.4 \pm 0.85 \%\end{array}$ & $1 \mu \mathrm{M}$ & 5 & $\begin{array}{r}-12.0 \pm 3.8 \% \\
-4.1 \pm 0.8 \%\end{array}$ & 5 & $+^{a}$ & & 0 \\
\hline \multicolumn{10}{|l|}{ Cauda (m) } \\
\hline Freq. & 277 & $1.35 \pm 0.14 / \mathrm{min}$ & $300 \mathrm{nM}$ & 4 & $1.4 \pm 0.16 / \mathrm{min}$ & 4 & 0 & & $1.32 \pm 0.32 / \mathrm{min}$ \\
\hline Ampl. & 154 & $3.5 \pm 0.61 \mathrm{mN}$ & & & $4.1 \pm 0.58 \mathrm{mN}$ & & 0 & & $2.6 \mathrm{mN}$ \\
\hline
\end{tabular}

${ }^{\mathrm{a} C}$ Cumulatively added after maximum xOT effect; Ampl., amplitude; freq., frequency.

$1.17 \pm 0.2$ vs $9.7 \pm 0.88 \mathrm{mN}$ for $\mathrm{NA} ; P<0.05, n=4$ for both; Fig. $1 \mathrm{~F}$ and $\mathrm{G})$. This finding was consistently observed and should not reflect damage to the tissue, as 4-AP $(10 \mathrm{mM})$, a non-selective blocker of voltagesensitive $\mathrm{K}^{+}$channels, induced a comparably strong contraction in both the cauda $(\mathrm{m})$ and the cauda (d), ( $n=3$ for both; data not shown).

\section{Involvement of epididymal ADRA}

The relative contribution of $\alpha_{1}$ - (ADRA 1 ) and $\alpha_{2}$-ADRA (ADRA2) to the epididymal NA effects has been studied with selective ADRA blockers. In the proximal duct regions, the NA-induced contraction was hardly affected by the ADRA1 antagonist prazosin $(1 \mu \mathrm{M}, n=3$; data not shown), but abolished by the ADRA2 inhibitor yohimbine $(10 \mu \mathrm{M})$. After prior application of yohimbine, NA induced a progressive and sustained suppression of phasic activity and a decrease in basal tone by $15.6 \pm 3.2 \%(P<0.05, n=5$; Fig. 2A). Cumulatively applied, yohimbine was able to reverse the NA-induced contraction ( $n=3$; Fig. 2B). The latter yohimbine effect was preceded by an initial contraction spike, possibly caused by reversion of an ADRA2-mediated inactivation of voltage-sensitive $\mathrm{Ca}^{2+}$ channels $\left(\mathrm{G}_{\mathrm{o}}\right.$ effect).

Contrary to the proximal duct regions, yohimbine $(10 \mu \mathrm{M})$ had no significant effect on the NA-induced contraction in the mid-cauda ( $n=3$; data not shown). By contrast, the excitatory effect of NA in the cauda (m) was significantly reduced after prior application of prazosin $(1 \mu \mathrm{M})$ by $92.4 \pm 1.5 \% \quad(P<0.05, \quad n=3$; Fig. 2C), indicating a quantitative dominance and functional significance of muscular ADRA1 in this region. Using yohimbine, we finally investigated the possibility that neuronal autoinhibition through prejunctional ADRA2 may underlie the weak responsiveness to NA in the cauda (d). However, application of the blocker $(10 \mu \mathrm{M})$ had no significant effect on a subsequent NA-induced contraction in this subregion $(n=3$; data not shown).

\section{Contractile effects of $\left[\mathrm{Thr}^{4}, \mathrm{Gly}^{7}\right] \mathrm{OT}$ and vasopressin}

At higher concentrations, a significant crosstalk of OT with vasopressin receptors (VPR) can occur (Burbach et al. 1995). In order to distinguish between receptorspecific and non-specific epididymal actions of OT, the selective OT agonist $\left[\mathrm{Thr}^{4}\right.$, Gly $\left.{ }^{7}\right] \mathrm{OT}$ (xOT) and vasopressin (AVP) were used in this study. The results are summarized in Table 1.

In both the epididymal caput and corpus preparations, the contraction modulatory effects of xOT greatly resembled those of OT (Fig. $3 \mathrm{~B}$ and D). In the caput, xOT induced significant increases $(P<0.05, n=4)$ in both SC frequency and basal tone, whereas in the corpus, both contraction parameters were significantly decreased $(P<0.05, n=5)$. The minimum/maximum effective concentrations of $x O T$ were $10^{-8} \mathrm{M} / 10^{-7} \mathrm{M}$ in the caput, and amounted to $10^{-7} \mathrm{M} / 10^{-6} \mathrm{M}$ in the corpus (Fig. 3A and $\mathrm{C}$ ). Hence, in the caput, the contractile responsiveness to xOT was about 10 times higher than in the corpus, which is also reflected by the corresponding $\mathrm{EC}_{50}$ values (Table 1). Interestingly, AVP $(30 \mathrm{nM})$, cumulatively applied after maximum xOT effects, induced (further) contraction in caput as well as in corpus segments. AVP $(300 \mathrm{nM})$ further reinforced contraction in caput segments, whereas in the corpus no additional effects could be observed (Fig. 3B and D).

In the cauda $(\mathrm{m})$, the contractile effects of OT (500 nM) and $\mathrm{xOT}(300 \mathrm{nM}$; Fig. 3F) were also very similar and AVP at a concentration of $300 \mathrm{nM}$ almost mimicked these effects (Table 1). In addition, AVP showed to induce caudal contraction in the same concentration range (between $10^{-7}$ and $3 \times 10^{-7} \mathrm{M}$ ) as $\mathrm{xOT}$ (Fig. $3 \mathrm{E}, \mathrm{F}$ and $\mathrm{H}$ ), and cumulative application of $300 \mathrm{nM} \times \mathrm{OT}$ after 300 nM AVP hardly exerted an additional effect (Fig. 3G and $\mathrm{H})$.

\section{Mechanisms of OTR response in the epididymal duct}

Epithelium-denuded proximal duct segments were used to test whether epithelium-dependent mechanisms account 
A

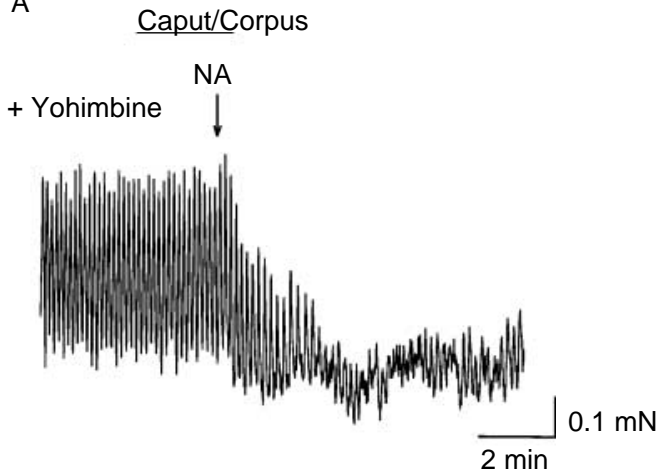

B
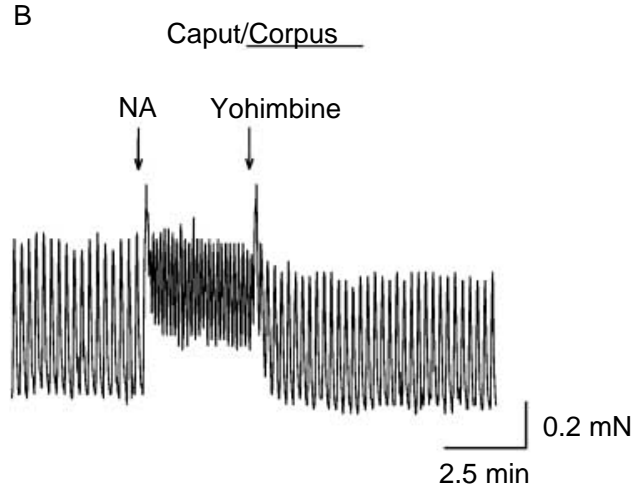

C

Cauda (m)

+ Prazosin

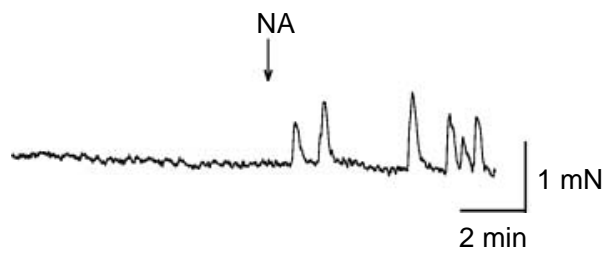

Figure 2 Receptors of NA in the course of the bovine epididymal duct. (A and B) Typical modulatory effects on NA-induced contraction in the proximal duct by prior (shown for the caput) and cumulative (shown for the corpus) application of yohimbine $(10 \mu \mathrm{M})$. (C) Representative effect of NA in the mid-cauda after prior application of the ADRA1 blocker prazosin $(1 \mu \mathrm{M})$.

for the OT-induced inhibitory net effect in the corpus. Triton X-100-perfused proximal duct segments shown to be free of epithelium (Mewe et al. 2006a) were devoid of SC, but still exhibited agonist-induced contraction, verifying intactness of the remaining muscle wall. OT induced temporary contraction in epithelium-denuded caput (Fig. 4A) as well as in epithelium-denuded corpus segments (Fig. 4B), indicating the presence of contractionmediating OTR in the epididymal peritubular musculature of both proximal duct regions.

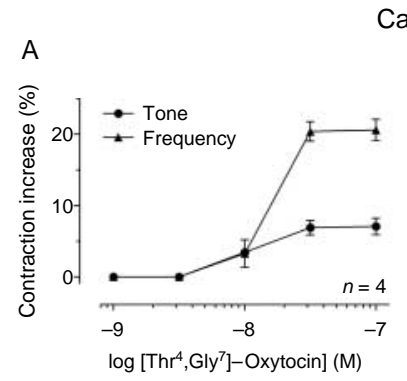

Caput

B
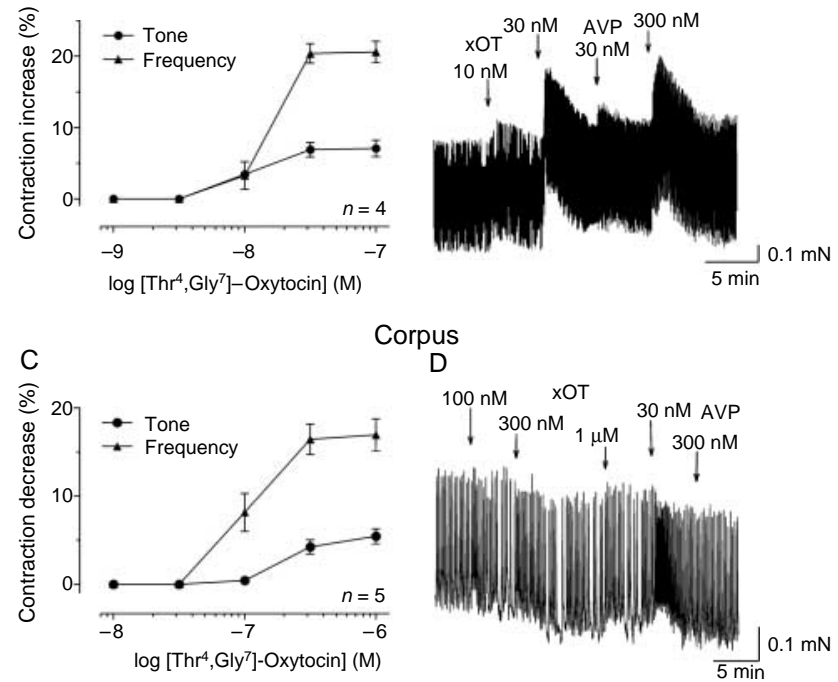

Corpus
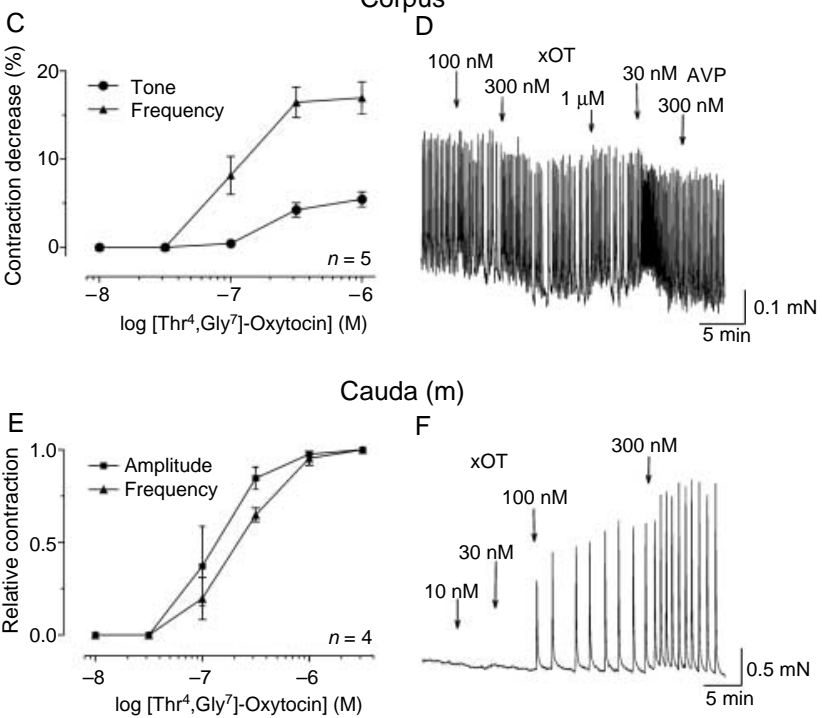

G

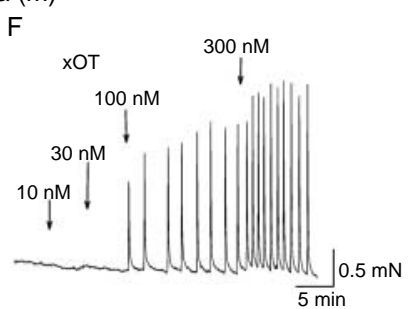

$\mathrm{H}$
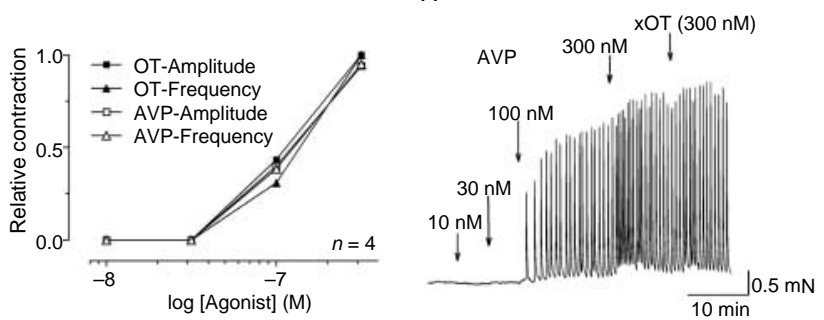

Figure 3 Contractile effects of xOT and AVP along the bovine epididymal duct. (A-F) Force recordings (B, D and F) and concentration-response curves $(A, C$ and $E$ ) demonstrating the effects of $x O T$ in the indicated duct regions. In addition, the responsiveness to different concentrations of AVP (in the proximal duct, cumulatively applied after maximum xOT effects) is shown (B, D and $H)$. (G) Concentrationresponse plots showing the relative potency of xOT and AVP to induce contraction in the cauda $(\mathrm{m})$. Increases in contraction amplitude and frequency were normalized to the respective maximum values of xOT at $300 \mathrm{nM}$.

Since OTappears to be involved in epididymal androgen regulation (Nicholson \& Jenkin 1994), we tested the SC modulatory effects of dihydrotestosterone (DHT) $(100 \mathrm{nM}$ to $100 \mu \mathrm{M}$ ). The biologically active metabolite of testosterone induced concentration-dependent relaxation in the proximal duct segments with a maximum effective concentration being $100 \mu \mathrm{M}$ ( $n=3 /$ region; Fig. 4C). Finally, involvement of an epithelium-dependent endogenous nitric oxide (NO) or prostaglandin production 

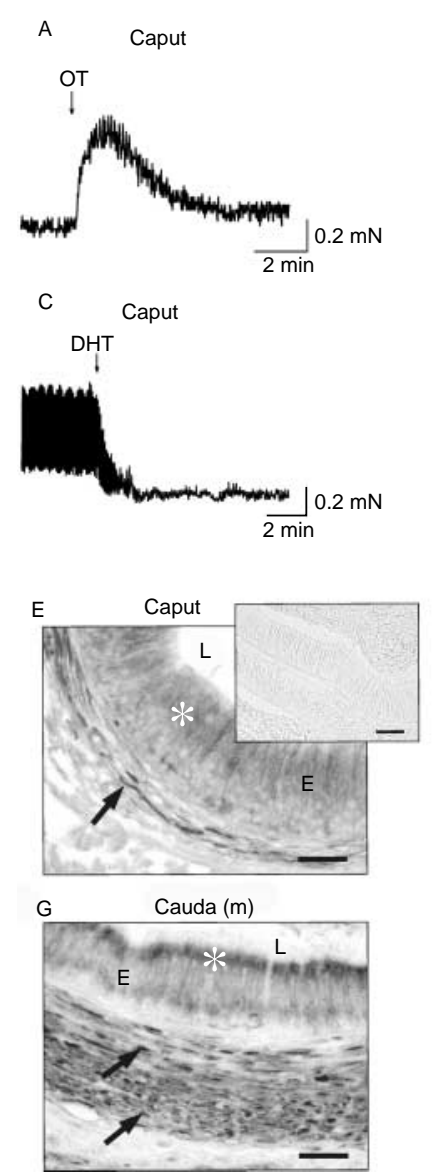

Figure 4 Mechanisms of OT response and OT receptors in the bovine epididymal duct. (A and B) Typical effects of OT in epithelium-denuded caput and corpus segments. Inhibitory effect of (C) DHT $(100 \mu \mathrm{M})$ on $\mathrm{SC}$ in the proximal duct and (D) OT in intact corpus segments after prior application of L-NAME (1 mM). (E-G) Immunohistochemical analysis of OTR expression in cross-sections of the indicated duct regions revealed immunoreactivity in peritubular smooth muscle cells (indicated by black arrows) and in the epithelium (white asterisks) in all duct regions. $E$, epithelium; $L$, lumen; bars 50 and $100 \mu \mathrm{m}$ for the inset in (E) showing a negative control with normal mouse serum. $(\mathrm{H})$

Detection of mRNA transcripts of the OTR gene by RT-PCR. A 550 bp DNA fragment could be detected after agarose gel electrophoresis of $20 \%$ of the PCR products using caput, corpus and cauda $(\mathrm{m})$ cDNAs as template.

in the OT effect in intact corpus segments was tested. Prior application of neither the NO synthase inhibitor L-NAME ( $1 \mathrm{mM}, n=4$; Fig. 4D) nor the cyclooxygenase (COX) inhibitor indomethacin $(20 \mu \mathrm{M}, n=4$; data not shown) reversed the inhibitory OT effects.

\section{Detection of epididymal OTR}

In agreement with the contractility studies, immunohistochemical analysis revealed expression of OTR in many, but not all, peritubular smooth muscle cells in the epididymal caput (Fig. 4E) and corpus regions (Fig. 4F), as well as in the circular and longitudinal muscle layers at the level of the mid-cauda (Fig. 4G).
Immunoreactivity against the OTR antibody was also apparent in the epithelial principal cells all along the duct, and is particularly pronounced near the apical pole in the cauda $(\mathrm{m})$. On control sections with the primary antibody replaced by PBS or normal mouse serum, no staining was detected as exemplary shown for the caput in Fig. 4E inset.

Conventional RT-PCR performed with preparations from the caput, corpus and cauda $(\mathrm{m})$ region confirmed expression of OTR in the epididymal duct. Specific primers of the bovine OTR gene yielded robust signals for OTR gene transcripts in all analyzed duct regions (Fig. $4 \mathrm{H}$ ).

\section{Discussion}

The results of the present study extend the concept of the epididymis as tissue target of OT and NA. Both ejaculation-relevant agonists exerted regionally varying effects in the bovine epididymal duct, ranging from relaxation to massive contraction. OTR could be detected in the peritubular musculature all along the epididymal duct, and NA-induced contraction was found to be mediated by different $\alpha$-ADRA subtypes in proximal and distal duct regions.

\section{Regional effects of (x)OT and AVP}

OT elicited contraction in the caput and particularly in the cauda $(\mathrm{m})$ but relaxing net effects in the corpus and cauda (p). The latter finding was unexpected since OT has been generally thought to stimulate epididymal contractility in vivo (Melin 1970, Nicholson et al. 1999, Assinder et al. 2000) and in vitro (Hib 1974, Filippi et al. 2002, Studdard et al. 2002). However, these authors primarily investigated the caput and cauda epididymidis. Our observation of a markedly decreasing responsiveness to OT from the cauda $(\mathrm{m})$ towards the ductus deferens is consistent with the findings of Maggi et al. (1987), who, in the boar, found a twofold greater concentration of OTR in the epididymis than in the vas deferens.

The contractile effects of OT in the bovine epididymal duct can be considered to be largely OTR specific. It is well known that the currently known AVP/OT receptor subtypes show significant structural homology and that the receptor selectivity of both OT and AVP for their own receptors is low (Burbach et al. 1995). However, the selective OTR agonist $x O T$ almost mimicked the contractile effects of OT in the present study, pointing to OTRs as main mediators of the observed OT effects. Nevertheless, relatively high concentrations of both OT and $\mathrm{xOT}$ were necessary to affect contractility in the bull epididymis. Studdard et al. (2002) demonstrated a minimum effective concentration of OT being even $<10^{-12} \mathrm{M}$ in the rat caput, and Murphy et al. (1987) 
found a circulating OT level of only about $10^{-11} \mathrm{M}$ at ejaculation in humans. Hence, great species-dependent differences in OT release and responsiveness to the peptide appear to exist. In addition, local OT production in the epididymis must be considered. Knickerbocker et al. (1988) established a physiological level of OT in the ovine epididymis to be about $10^{-10} \mathrm{M}$, and Nicholson et al. (1984) detected tissue concentrations of OT in the testis being 100-fold higher than those in plasma. The $\mathrm{EC}_{50}$ values ascertained in the present study for $\mathrm{xOT}$ to elicit contraction in the cauda region suggest a systemic OT level of at least $10^{-7} \mathrm{M}$ at ejaculation in the bull.

The SC-relaxing effects of OT in the corpus and cauda (p) appear to be epithelium dependent, since the peptide hormone induced contraction in epithelium-denuded segments from both the epididymal caput and corpus regions. In accordance with the findings in several other species (Maggi et al. 1987, Einspanier \& Ivell 1997, Frayne \& Nicholson 1998, Whittington et al. 2001, Filippi et al. 2002), OTR immunoreactivity could be localized to the peritubular muscle wall as well as to the epithelium of the bovine epididymal duct. In this context, the possibility was tested whether OT, in addition to directly stimulating the peritubular contractile cells, amplifies the synthesis of relaxing paracrine factors like $\mathrm{NO}$ and prostaglandin $\mathrm{E}_{2}$ in the epithelial (basal) cells particularly at the level of the corpus and the cauda (p) (see Wong et al. 1999, Lazarus et al. 2002, Mewe et al. 2006b). However, neither L-NAME nor $20 \mu \mathrm{M}$ indomethacin (suggested to selectively block the COX-1 at this concentration) reversed the inhibitory OT effects in these regions, raising the question about other relaxation-inducing signalling pathways triggered by OT. These may involve the production of DHT, which, in the present study, showed to induce relaxation in the proximal duct segments. Epididymal function is androgen dependent and relies specifically on the $5 \alpha$-reduced metabolite of testosterone, DHT (see Thackare et al. 2006). OT was found to stimulate $5 \alpha$-reductase activity in the epididymal epithelial compartment (Nicholson \& Jenkin 1994) and possibly, this action of OT also underlies the SC inhibitory net effects of OT/xOT in the mid-epididymis.

The data produced in this study also suggest a functional role of AVP in the bovine epididymal duct. AVP is released into the circulation from the posterior pituitary during coitus (Sharma et al. 1972, Murphy et al. 1987). In both proximal duct regions, cumulatively applied AVP exerted additional contraction after maximum effective xOT concentrations, indicative of the presence of specific VPR. In addition, contrary to OT/xOT, AVP did not induce relaxation in the corpus and therefore appears to stimulate different signal transduction systems at least in this region. Higher doses of AVP have also been shown to stimulate epididymal contractility in rabbits, rams and rats (Kihlstrom \& Agmo 1974, Knight 1974, Jaakola \& Talo 1981) and increase the seminal volume and sperm content in the ejaculate of the rabbit (Kihlstrom \& Agmo 1974). Using lower doses of AVP, Nicholson et al. (1999) described a lack of effect in the sheep cauda epididymidis. This is in accordance with the findings in the present study. Similar concentrations of AVP and xOT were necessary to induce contraction in the cauda (m), and both peptides administered cumulatively at high doses showed no significant additive effect. Hence, in the cauda (m), VPR seem to be absent and AVP may act through OTR (see also Knight 1974, Nicholson et al. 1999).

\section{Regional effects of $N A$}

NA was found to promote epididymal motility in all duct regions with distally increasing potency. Interestingly, the contraction elicited by both OT and NA was highest in the cauda $(\mathrm{m})$ and clearly decreased in force and duration in the even more muscular (Baumgarten et al. 1971) ductus deferens (p.ep.), indicative of a lower abundance or a different assembly of the respective contraction-mediating receptors in this part of the ductus deferens.

The present results provide compelling evidence that the NA-induced contraction in the bovine epididymis is primarily mediated by postjunctional ADRA2 in the proximal duct regions and by ADRA 1 in the mid-cauda. The latter is consistent with the findings in rats (Ventura \& Pennefather 1991, 1994, Chaturapanich et al.2002) and guinea pigs (Haynes \& Hill 1996), whereas in the proximal cauda of rats, both $\alpha_{1}$ - and $\alpha_{2}$-ADRAs mediate contraction (Chaturapanich et al. 2002). Postjunctional ADRA2 have also been found in the cauda epididymidis of guinea pigs; however, they appear to only potentiate the ADRA1-mediated contractile responses (Haynes \& Hill 1996). Hence, a distally increasing physiological significance of ADRA1 and a decreasing significance of ADRA2 as main mediators of NA-induced contraction in the epididymal duct can be assumed.

A physiological peculiarity was found in the cauda (d) newly described here. In comparison with the adjacent regions, this duct section was characterized by a very faint contractile responsiveness not only to OT, but also to NA. Although the underlying mechanisms still have to be elucidated, a comparably lower density of postjunctional ADRA1 as well as 'facilitating' ADRA2 in this subregion have to be taken into consideration. The possibility that neuronal autoinhibition through prejunctional ADRA2 is responsible for the weak NA effect in the cauda (d) seems unlikely since prior application of yohimbine failed to increase NA-induced contraction.

\section{Physiological implications}

The present study concurs that OT and NA play an important role in regulating epididymal contractility. 
The bimodal effects of OT in the proximal duct regions could ensure selective emptying of the cauda and prevent excessive sperm progression through the middle portion of the epididymal duct during the ejaculatory process. In conjunction with our previous finding of particularly strong inhibitory effects of cGMP in the corpus (Mewe et al. 2006b), the present data confirm our assumption of time-dependent sperm maturation processes in this duct region.

In view of the fact that both systemic OT and NA are released at ejaculation and promote sperm transfer from the epididymal storage to the ductus deferens, it can be speculated that the distally decreasing contractile effects of both factors ensure anterograde emission of sperm at the time of ejaculation. This proposal is supported by the comparably weak contractile responsiveness to both OT and NA in the cauda (d), thereby possibly facilitating orthograde sperm transport. Therefore, the results of the present study may also provide new insights into the epididymal control of spatio-temporal sperm maturation processes and anterograde ejaculation.

\section{Acknowledgements}

We would like to thank Telse Kock and Annett Hasse for their expert technical help and the Deutsche Forschungsgemeinschaft for financial support (Mi 637/1-1). The authors declare that there is no conflict of interest that would prejudice the impartiality of this scientific work.

\section{References}

Assinder SJ, Carey M, Parkinson T \& Nicholson HD 2000 Oxytocin and vasopressin expression in the ovine testis and epididymis: changes with the onset of spermatogenesis. Biology of Reproduction 63 448-456.

El-Badawi A \& Schenk EA 1967 The distribution of cholinergic and adrenergic nerves in the mammalian epididymis. A comparative histochemical study. American Journal of Anatomy 121 1-14.

Baumgarten HG, Holstein AF \& Rosengren E 1971 Arrangement, ultrastructure, and adrenergic innervation of smooth musculature of the ductuli efferentes, ductus epididymidis and ductus deferens of man. Zeitschrift fur Zellforschung und Mikroskopische Anatomie $12037-79$.

Berndtson WE \& Igboeli G 1988 Spermatogenesis, sperm output and seminal quality of Holstein bulls electroejaculated after administration of oxytocin. Journal of Reproduction and Fertility $\mathbf{8 2}$ $467-475$.

Billups KL, Tillman SL \& Chang TSK 1990 Ablation of the inferior mesenteric plexus in the rat: alterations of sperm storage in the epididymis and vas deferens. Journal of Urology 143 625-629.

Burbach JP, Adan RA, Lolait SJ, van Leeuwen FW, Mezey E, Palkowits M \& Barberis C 1995 Molecular neurobiology and pharmacology of the vasopressin/oxytocin receptor family. Cellular and Molecular Neurobiology 15 573-595.

Chaturapanich G, Maythaarttaphong S, Verawatnapakul V \& Pholpramool C 2002 Mediation of contraction in rat cauda epididymidis by alpha-adrenoceptors. Reproduction 124 887-892.

Chomczynski P \& Sacchi N 1987 Single step method of RNA isolation by acid guanidinium thiocyanate-phenol-chloroform extraction. Analytical Biochemistry 162 156-159.
Cosentino MJ \& Cockett ATK 1986 Review article: structure and function of the epididymis. Urological Research 14 229-240.

Cosentino MJ, Takihara H, Burhop JW \& Cockett ATK 1984 Regulation of rat caput epididymidis contractility by prostaglandins. Journal of Andrology 5 216-222.

Einspanier A \& Ivell R 1997 Oxytocin and oxytocin receptor expression in reproductive tissues of the male marmorset monkey. Biology of Reproduction $\mathbf{5 6}$ 416-422.

Filippi S, Vannelli GB, Granchi S, Luconi M, Crescioli C, Mancina R, Natali A, Brocchi S, Vignozzi L, Bencini E, Noci I, Ledda F, Forti G \& Maggi M 2002 Identification, localization and functional activity of oxytocin receptors in epididymis. Molecular and Cellular Endocrinology 193 89-100.

Filippi S, Vignozzi L, Vannelli GB, Ledda F, Forti G \& Maggi M 2003 Role of oxytocin in the ejaculatory process. Journal of Endocrinological Investigation 26 82-86.

Filippi S, Morelli A, Vignozzi L, Vannelli GB, Marini M, Ferruzzi P, Mancina R, Crescioli C, Mondaini N, Forti G, Ledda F \& Maggi M 2005 Oxytocin mediates the estrogen-dependent contractile activity of endothelin-1 in human and rabbit epididymis. Endocrinology 146 3506-3517.

Frayne J \& Nicholson HD 1998 Localization of oxytocin receptors in the human and macque monkey male reproductive tracts: evidence for a physiological role of oxytocin in the male. Molecular Human Reproduction 4 527-532.

Glover TD \& Nicander L 1971 Some aspects of structure and function in the mammalian epididymis. Journal of Reproduction and Fertility 13 39-50.

Harris GC, Frayne J \& Nicholson HD 1996 Epididymal oxytocin in the rat: its origin and regulation. International Journal of Andrology 19 278-286.

Haynes JM \& Hill SJ 1996 Alpha-adrenoceptor mediated responses of the cauda epididymis of guinea-pig. British Journal of Pharmacology $1191203-1210$.

Hib J 1974 The in vitro effects of oxytocin and vasopressin on spontaneous contractility of the mouse cauda epididymidis. Biology of Reproduction 11 436-439.

Hodson N 1970 The nerves of the testis, epididymis and scrotum. In The Testis, 1 edn, pp 47-99. Eds AD Johnson, WR Gomes \& NL Vandemark. New York: Academic Press.

Ivell R, Balvers M, Rust W, Bathgate R \& Einspanier A 1997 Oxytocin and male reproductive function. Advances in Experimental Medicine and Biology 424 253-264.

Jaakola UM \& Talo A 1981 Effects of oxytocin and vasopressin on electrical and mechanical activity of the rat epididymis in vitro. Journal of Reproduction and Fertility 63 47-51.

Kempinas WD, Suarez JD, Roberts NL, Strader L, Ferrell J, Goldman JM \& Klinefelter GR 1998 Rat epididymal sperm quantity, quality, and transit time after guanethidine-induced sympathectomy. Biology of Reproduction 59 890-896.

Kihlstrom JE \& Agmo A 1974 Some effects of vasopressin on sexual behaviour and seminal characteristics in intact and castrated rabbits. Journal of Endocrinology 60 445-453.

Knickerbocker JJ, Sawyer HR, Amann RP, Tekpetery FR \& Niswender GD 1988 Evidence for the presence of oxytocin in the ovine epididymis. Biology of Reproduction 39 391-397.

Knight TW 1974 A qualitative study of factors affecting the contractions of the epididymis and ductus deferens of the ram. Journal of Reproduction and Fertility 40 19-29.

Lazarus M, Munday CJ, Eguchi N, Matsumoto S, Killian GJ, Kubata BK \& Urade Y 2002 Immunohistochemical localization of microsomal PGE synthase-1 and cyclooxygenases in male mouse reproductive organs. Endocrinology 143 2410-2419.

Maggi M, Malozowski S, Kassis S, Guardabasso V \& Rodbard D 1987 Identification and characterization of two classes of receptors for oxytocin and vasopressin in porcine tunica albuginea, epididymis and vas deferens. Endocrinology 120 986-994. 
Melin P 1970 Effects in vivo of neurohypophysial hormones on the contractile activity of accessory sex organs in male rabbits. Journal of Reproduction and Fertility 22 283-292.

Mewe M, Bauer CK, Schwarz JR \& Middendorff R 2006a Mechanisms regulating spontaneous contractions in the bovine epididymal duct. Biology of Reproduction 75 651-659.

Mewe M, Bauer CK, Müller D \& Middendorff R 2006b Regulation of spontaneous contractile activity in the bovine epididymal duct by cyclic guanosine 5'-monophosphate-dependent pathways. Endocrinology 147 2051-2062.

Middendorff R, Müller D, Wichers S, Holstein AF \& Davidoff MS 1997 Evidence for production and functional activity of nitric oxide (NO) in seminiferous tubules and blood vessels of the human testis. Journal of Clinical Endocrinology and Metabolism 82 4154-4161.

Moore HDM 1995 Post-testicular sperm maturation and transport in the excurrent ducts. In Gametes - The Spermatozoon, pp 140-156. Eds JG Grudzinskas \& JL Yovich. Cambridge: Cambridge University Press.

Murphy MR, Seckl JR, Burton S, Checkley SA \& Lightman SL 1987 Changes in oxytocin and vasopressin secretion during sexual activity in men. Journal of Clinical Endocrinology and Metabolism 65 738-741.

Nicholson HD \& Jenkin L $19945 \boldsymbol{\alpha}$-reductase activity increased by oxytocin in the rat testis. In Function of Somatic Cells in the Testis, pp 278-285. Ed. A Bartke. New York: Verlag.

Nicholson HD, Swann RW, Burford GD, Wathes DC, Porter DG \& Pickering BT 1984 Identification of oxytocin and vasopressin in the testis and adrenal tissue. Regulatory Peptides 8 141-146.

Nicholson HD, Parkinson TJ \& Lapwood KR 1999 Effects of oxytocin and vasopressin on sperm transport from the cauda epididymis in sheep. Journal of Reproduction and Fertility 117 299-305.

Peri A, Fantoni G, Granchi S, Vannelli GB, Barni T, Amerini S, Pupilli C, Barbagli G, Serio M, Maggi M \& Forti G 1998 Endothelin1 is synthesized and biologically active in human epididymis via a paracrine mode of action. Steroids 63 294-298.

Pholpramool C, Triphrom N \& Din-Udom A 1984 Intraluminal pressures in the seminiferous tubules and in different regions of the epididymis in the rat. Journal of Reproduction and Fertility $\mathbf{7 1}$ 173-179.

Ratnasooriya WD \& Wadsworth RM 1990 Impairment of fertility of male rats with prazosin. Contraception 41 441-447.
Ricker DD 1998 The autonomic innervation of the epididymis: its effects on epididymal function and fertility. Journal of Andrology 19 $1-4$.

Ricker DD, Chamness SL, Hinton BT \& Chang TSK 1997 Partial sympathetic denervation of the rat epididymis permits fertilization but inhibits embryo development. Journal of Andrology 18 131-138.

Schams D, Baumann G \& Leidl W 1982 Oxytocin determination by radioimmunoassay in cattle. II. Effect of mating and stimulation of the genital tract in bulls, cows and heifers. Acta Endocrinologica 99 218-223.

Sharma SC, Fitzpatrick RJ \& Ward WR 1972 Coital-induced release of oxytocin in the ram. Journal of Reproduction and Fertility 31 488-489.

Studdard PW, Stein JL \& Cosentino MJ 2002 The effects of oxytocin and arginine vasopressin in vitro on epididymal contractility in the rat. International Journal of Andrology 25 65-71.

Thackare H, Nicholson HD \& Whittington K 2006 Oxytocin - its role in male reproduction and new potential therapeutic uses. Human Reproduction Update 12 437-448.

Ventura S \& Pennefather JN 1991 Sympathetic co-transmission to the cauda epididymis of the rat: characterization of postjunctional adrenoceptors and purinoceptors. British Journal of Pharmacology $102540-544$.

Ventura S \& Pennefather JN 1994 Alpha2-adrenoceptor binding sites vary along the length of the male reproductive tract: a possible basis for the regional variation in response to field stimulation. European Journal of Pharmacology 254 167-173.

Whittington K, Assinder SJ, Parkinson T, Lapwood KR \& Nicholson HD 2001 Function and localization of oxytocin receptors in the reproductive tissue of rams. Reproduction 122 317-325.

Wong PY, Chan HC, Leung PS, Chung YW, Wong YL, Lee WM, Ng V \& Dun NJ 1999 Regulation of anion secretion by cyclooxygenase and prostanoids in cultured epididymal epithelia from the rat. Journal of Physiology 514 809-820.

Received 10 May 2007

First decision 1 June 2007

Accepted 14 June 2007 